\title{
Trabzon 100.Yıl Parkı ve Çevresinin Rekreasyon Potansiyelinin Saptanması
}

\author{
Elif BAYRAMOĞLU ${ }^{1 *}$, Nazlı Mine YURDAKUL ${ }^{1}$ \\ ${ }^{1}$ Karadeniz Teknik Üniversitesi, Orman Fakültesi, Peyzaj Mimarlığı Bölümü, 61080, TRABZON
}

\section{Öz}

Kentler insanların günlük etkinliklerini gerçekleştirdikleri yaşam ortamlarıdır. Ancak günümüzde kent nüfusunun hızla artmasıyla kent merkezlerindeki yeni yerleşim merkezleri ortaya çıkmıştır. Bu durum kentteki doğal yaşanabilir alanların azalmasına, ulaşım ve sağlık gibi sorunların ortaya çıkmasına sebep olmuştur. Kent insanı rekreatif etkinlikleri için kent dışında daha doğal alanları tercih etmeye başlamış̦ır. Günümüz planlamacıları ise oluşan soruna yeni çözüm önerileri getirmek için rekreasyon alanlarını ve kalitesini arttırmak amacıyla kentlerde yeşil alanları arttırmaya yönelik çalışmalar yürütmektedirler. Çalışma Trabzon ili kent merkezinde bulunan ve kullanım olanağı açısından oldukça zengin açık yeşil alan bakımından zengin; 100.Yıl park alanının rekreasyonel potansiyelini belirlemek amacıyla yapılmıştır. Bu amaçla Gülez tarafindan ortaya konulan "Açıkhava Rekreasyon Potansiyelinin Saptanması" için geliştirilen ve daha sonra Gülez (1990) tarafindan Orman içi rekreasyonel potansiyelin saptanması" amacıyla uyarlanmış yöntem ele alınmıştır. Daha sonraki süreçte bu yöntemin verilerine göre alan için uygun rekreasyon potansiyel modeli oluşturulmuştur. Alan için belirlenen tüm kriterler 11 uzman peyzaj mimarı tarafindan değerlendirilmiş ve hesaplamalar yapılmıştır. Bu değerlendirme ve hesaplamalara göre alanın en çok puan aldığı kriterler peyzaj değeri, iklim değeri, ulaşılabilirlik olarak belirlenmiştir. Yanı sıra alan rekreatif kolaylık ve olumsuz etmenlerden daha az puanlar aldığı gözlemlenmiştir. Çalışma ile 100.Yıl park alanın peyzaj değerinin oldukça yüksek olduğu belirlenmiştir. Bununla birlikte alan içerisinde belirlenen olumsuz etmenleri yok etmek ve alandan daha fazla verim sağlamak amacyyla çeşitli öneriler sunulmuştur.

Anahtar Kelimeler: Kentsel açık alan, rekreasyon, Gülez Yöntemi, rekreasyon potansiyeli.

\section{Determination of Recreation Potential of Landscape Values of Trabzon 100. YIl Park and Environment}

\begin{abstract}
Cities are living environments where people perform their daily activities. However, with the rapid increase of the urban population, new settlement centers in urban centers have emerged. This situation led to the decrease of natural habitable areas in the city and problems such as transportation and health. Divorced from the nature of life as a result of the psychological and physical damage to people born in the city, it was affected negatively the progress of the formation of quality of life because of these events. Urban people started to prefer more natural areas outside the city for their recreational activities. Today's planners are already undertaking efforts to increase green areas in cities and recreation areas in order to increase the quality of proposals to bring new solutions to the problems that occur. The aim of this study was to determine the recreational potential of the 100. Y1l Park, which is very rich in terms of natural values found in the Development District of Trabzon, and to develop suggestions for the findings. In this study, the method which was developed for "Determination of Outdoor Recreation Potential method by Gülez (1979) and then determined by Gülez (1990) in order to determine the Inland Recreation Potential, was taken into consideration. The appropriate recreation potential model was created. All the criteria for the area were evaluated by 11 expert landscape architects and calculations were made. According to these evaluations and calculations, the criteria with which the area was scored the most, were determined as landscape value, climate value, accessibility, and it was observed that the area received less points than the recreational and negative factors. It is determined that the landscape value of the area is very high with this study. However, various suggestions are presented in order to eliminate the negative factors determined in the field and to provide more efficiency from the area.
\end{abstract}

Keywords: Urban open space, recreation, Gülez Method, recreational potential.

\footnotetext{
*Sorumlu Yazar (Corresponding Author):

Elif BAYRAMOĞLU; Karadeniz Teknik Üniversitesi, Orman Fakültesi, Peyzaj

Mimarlığı Bölümü, 61080, Trabzon -Türkiye. Tel: +90 (462) 3774083,

E-mail: elifsol_@hotmail.com ORCID:0000-0002-6757-7766

Geliş (Received) : : 19.09.2019

Kabul (Accepted) : 06.01.2020

Basım (Published) : 15.04.2020
} 


\section{Giriş}

19. yüzyılda oluşan teknolojik gelişmeler ve sanayileşme insanların boş zamanlarına ayırdıkları vaktin azalmasına neden olmuştur (Çakır ve Çakır, 2012: 232; Surat, 2017: 248). Günlük yoğun ve monotonlaşan kent yaşamında yüzleşmek zorunda bırakıldığımız baskılardan en verimli şekilde kurtulma yollarından biri rekreasyonel alanlara yönelme olarak kendini göstermiştir (Yeşil ve Hacığlu, 2018: 681). Bu anlamda bakıldığında rekreasyon, zamanın insanlar üzerinde sonsuzluk etkisi yaratan, boş vakitlerini değerlendirmek amacıyla kişisel olarak doyum sağlayan faaliyetler olarak tanımlanmaktadır (Karaküçük, 2014). İnsanların psikolojik, sosyal fayda sağlamak amacıyla iş ve çalışma zamanları dışında kalan serbest vakitlerde yapılan etkinliklerdir (Tütüncü ve ark., 2011: 70). İnsanların rekreasyona duyduğu gereksinim çevrenin olumsuz etkilerinden uzaklaşmak, ruhsal bakımdan yenilenmek, yaşamlarındaki birçok sıkıntıdan kurtulmak, kendilerini geliştirme ihtiyaçlarına yönelik taleplerden ortaya çıkmıştır (Öztürk, 2005: 141; Axelsen, 2009: 331). Daha sonraları fiziksel ruhsal açıdan gereksinimlerini karşılamak adına insanlar boş ve serbest zamanlarında ekonomik açıdan bir beklenti olmaksızın rekreasyon alanlarına yönelmişlerdir (Şimşek ve Korkut, 2009: 317). Ortaya çıkan bu talepler ve eğilimleri etkileyen en önemli etmen ise kullanıcıları sosyo-ekonomik yapılarına bağlı değişkenlerdir (Jim, 1989: 19). Yanı sıra etkinlikler çok farklı olguyu kapsamakta ve çeşitlilik göstermektedir (Schiller, 2001:2).

Rekreasyon kişilerin kendi istekleri ile istedikleri zaman diliminde, kültürel ve ekonomik açıdan yaptıkları etkinliklerdir (Boman, 2013: 50). Rekreasyonda herhangi bir maddi kazanç ve beklenti söz konusu olmayıp fiziksel veya düşünsel yönde bir hareketlilik içerir. Bireysel ve topluluk halinde planlanmış ya da o anda karar verilmiş neşe sağlayan etkinliklerdir (Sağcan 1986: 50; Pehlivanoğlu 1987: 46). Bu alanlar; ulaşılabilirlik, kullanım şekli ve kolaylığı, sunduğu rekreasyonel olanaklar gibi etkenlere bağlı olarak kullanıcının almak istediğini vermesi ile birlikte farklı zaman aralıklarında ve farklı boyutlarda tercih edilmektedirler. Bireyler gün içerisinde sıklıkla meydanlar, oturma-dinleme alanları, kent içi parkları kullanırlar. Bunların yanı sıra günübirlik veya birkaç günlük etkinlikleri gerçekleştirmek amacıyla tercih edilen alanlar ise kentten uzak kırsal alanlardır. Bu alanlar insanların yoğun ve monoton baskıdan uzaklaşacakları hem doğal hem de kentten çok uzak olmayan kırsal alanlardaki bölgelerdir (Demirel, 1999: 1105).

$\mathrm{Bu}$ çalışma Trabzon kentinde sahil yolu üzerinde bulunan, doğal değerleri bakımından oldukça zengin ve sahil alanı olan ve 07.12.2018 tarihinde "Doğal Sit - Sürdürülebilir Koruma ve Kontrollü Kullanım Alanı" olarak statü değişikliği yapılmıştır. Çalışma kapsamında 100.Yı1 Parkı ve yakın çevresinde peyzaj değerlerinin rekreasyon potansiyelinin saptanması, güçlü ve zayıf yönlerinin ortaya konularak sahip olduğu firsatları ve karşı karşıya kaldığı tehditleri tespit edilmiştir. Çalışma Trabzon kent insanının 100. Yıl Parkı çalışma alanı özelinde, rekreasyon alanlarının mevcut rekreasyon potansiyellerinin belirlenmesine yönelik yapılmıştır.

\section{Materyal ve Metot}

\subsection{Materyal}

Çalışma Karadeniz Bölgesi'nin Karadeniz kıyı kuşağında yer alan ve kent merkezine yaklaşık olarak 4 km uzaklıktaki bir park alanında gerçekleştirilmiştir (Şekil 1). Çalışma alanı olarak belirlenen100.Yıl Parkı konum olarak Trabzon Forum AVM yanı ve sahil yolu üzerinde bulunmaktadır. Türk-Japon EYOF Hatıra Parkı'nı da çalışma alanına dâhil edilerek Trabzon Forum AVM çevresinin rekreasyonel değeri belirlenmiştir. Çalışma alanının park ve yakın çevresinin alınma sebebi ise; kullanım olanağı bakımından AVM çevresi, Türk-Japon EYOF Hatıra Parkı ve park alanı birlikte değerlendirilmektedir. Çalışma alanı 2014 yılına kadar sadece açık yeşil alan olarak kullanılmaktayken yeni sahil yolunun yapımı ile tekrar değiştirilmiştir. Tabiat Varlıklarını Koruma Genel Müdürlüğü tarafından “Trabzon Tabiat Varlıklarını Koruma Bölge Komisyonu’nun 26.10.2017 tarihli ve 817 sayılı kararı ile 100. Yıl Parkı Doğal Sit Alanının koruma statüsünün "Doğal Sit- Sürdürülebilir Koruma ve Kontrollü Kullanım Alanı” olarak tescillendi. Çalışma alanı içerisinde 300 kişilik restoran, dinlenme alanları, çocuk oyun alanları, piknik alanları ve otopark bulunmaktadır. Özellikle kentlinin hafta sonları merkezden uzaklaşmadan ailecek vakit geçirebilecekleri bir park halini almıştır (Şekil 2).

Çalışma alanı olarak değerlendirilen park, uzun dönemler boyunca atıl kalıp insanların kullanmadığı bir alandı. Ancak daha sonra insanların denize ulaşma, denizi kullanma arzusu ile açık yeşil alan olarak değerlendirildi. Sit alanı olarak belirlenen alan daha sonra Tabiat Varlıklarını Koruma Genel Müdürlüğü tarafindan "Trabzon Tabiat Varlıklarını Koruma Bölge Komisyonu'nun kararı ile 100. Yıl Parkı Doğal Sit Alanının koruma statüsünün "Doğal Sit- Sürdürülebilir Koruma ve Kontrollü Kullanım Alanı” olarak tescillendi. Bu çalışmada alanın sahip olduğu rekreasyonel potansiyel durumunun günümüzdeki halinin analiz edilmesi amaçlanmıştır. 


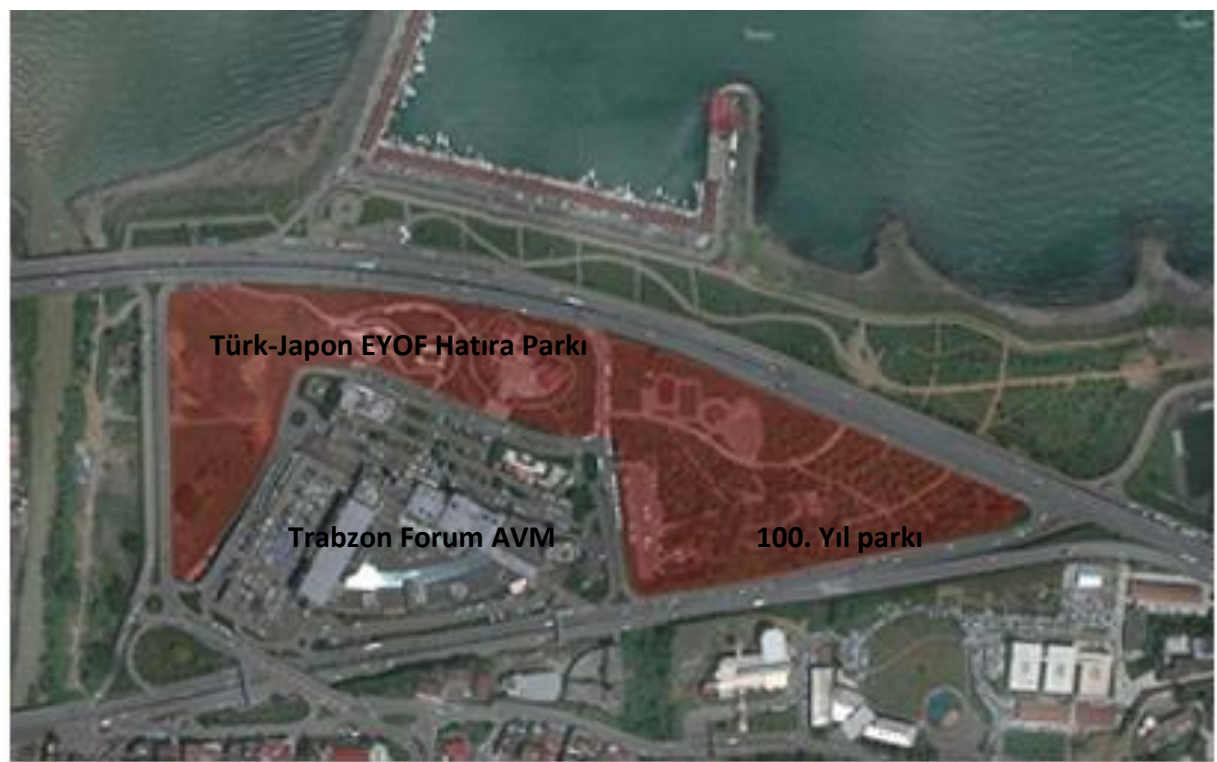

Şekil 1. Çalışma alanı
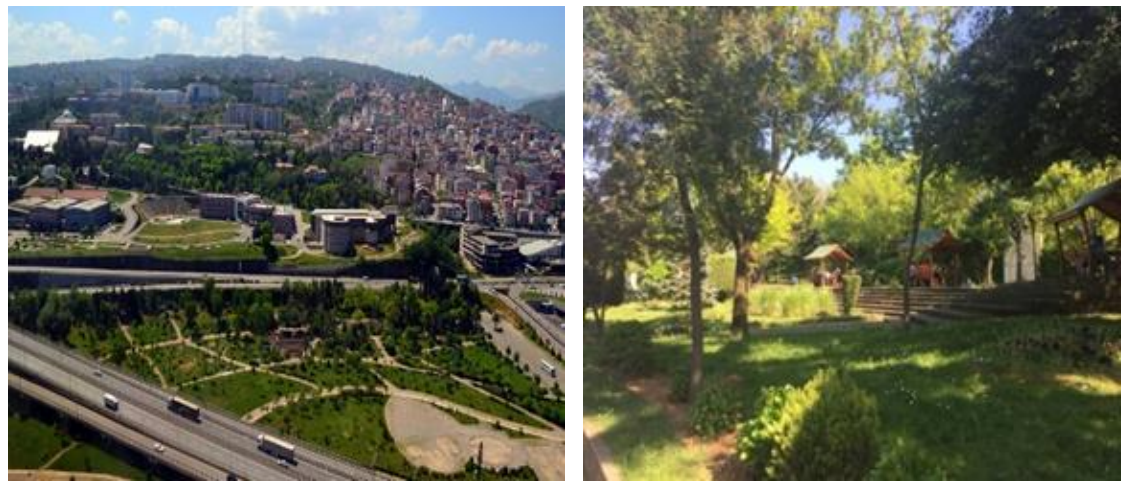

Şekil 2. Trabzon 100.Y1l Parkı etkinlik alanları

\subsection{Yöntem}

Çalışmada yöntem olarak Gülez (1979)'in uyguladığı rekreasyonel potansiyeli saptama yöntemi kullanılmıştır. Gülez (1979) yöntemi ilk olarak “Açıkhava Rekreasyon Potansiyelinin Saptanması” çalışmasında kullanmış ve daha sonra Gülez (1990) "Orman içi rekreasyonel potansiyelin saptanması” çalışmasına uyarlanmıştır. Yöntem bu amaçla bir çok farklı akademik çalışmada da kullanılmıştır (Gülez ve Demirel 2004:26-34; Y1lmaz vd., 2009, Çalık vd., 2013: 35-45; Sandal ve Karademir, 2013: 30-36; Surat vd., 2009:200-250, Yeşil ve Hacioğlu, 2018: 683-685).

Yönteme göre açık mekân rekreasyonel potansiyelinin belirlenmesi Peyzaj Değeri, İklimi, Ulaşılabilirlik Durumu, Rekreatif Kolaylıklar ile alanda bulunan bazı Olumsuz Etkenler kriter olarak belirlenerek değerlendirilmiştir. Bir alanın rekreasyonel potansiyelini belirlemek alanın sahip olduğu değerlerin belirlenmesi ile ortaya çıkar. Bu amaçla alana ait bütün değerler ele alınarak puanlanıp formülde yerine yerleştirilir. Yöntemi uygulamak amacıyla rekreasyonel potansiyeli arttıran ya da düşüren etmenlerin puanlamalarını içeren değerlendirme formları hazırlanmıştır. Gülez (1979)'in yöntemi oldukça pratik ve basit bir formül ile hesaplanmaktadır ve formül aşağıdaki şekilde ifade edilmektedir. Formülde yer alan ögelerin alabilecekleri maksimum puanların dağılımı P + $\dot{I}+\mathrm{U}+\mathrm{RK}+\mathrm{OE}=\mathrm{RP}(\%)$ ile hesaplanır. Yönteme göre formüldeki öğeler ve alabilecekleri puanların maksimum değerleri Tablo 1 'de verilmiştir (Yeşil ve Hacıoğlu, 2018:683-685). 
Tablo 1. Formüldeki Öğeler Ve Alabilecekleri Puanlar (Gülez, 1990: 134)

\begin{tabular}{lll}
\hline Sembol & Anlam & \\
\hline $\mathbf{P}$ & Peyzaj Değeri & 35 \\
$\mathbf{I}$ & İklim & 25 \\
$\mathbf{U}$ & Ulaşılabilirlik & 20 \\
$\mathbf{R K}$ & Rekreatif Kolaylik & 20 \\
$\mathbf{O E}$ & Olumsuz Etkenler & $0($ minimum -10$)$ \\
\% RP & Rekreasyon Potansiyeli & 100 \\
\hline
\end{tabular}

Formüle göre Peyzaj Değeri: Bir alanın rekreasyonel potansiyeli belirlenirken değerlendirilmesi gereken en önemli kriter o yerin peyzaj potansiyelidir. Formüle göre peyzaj değeri diğer kriterlerden en fazla \% 35 'lik bir ağırlıkla değerlendirilmiştir (Tablo 2).

Tablo 2. Peyzaj Değerini Oluşturan Öğelerin Aldıkları Puanlar (Gülez, 1990: 135)

\begin{tabular}{|c|c|c|c|c|}
\hline \multirow[t]{10}{*}{ Öğe } & Ögenin Özellikleri & Açıklama & \multicolumn{2}{|c|}{ AMP } \\
\hline & Alanın Büyüklüğü & $>10$ & 4 & \\
\hline & & $0,5-1$ ha & 3 & 4 \\
\hline & & $1-5$ ha & 2 & \\
\hline & & $5-10$ ha & 1 & \\
\hline & Bitki örtüsü & Ağaçlık, çalılık, çayırlık & $7-8$ & \\
\hline & & A ğaçlık, çayırlık & $6-7$ & \\
\hline & & Çalılık, çayırlık, seyrek ağaçlık & $5-6$ & \\
\hline & & Çayırlık, seyrek ağaçlık & $3-4$ & 8 \\
\hline & & Çalılık, çayırlık & $3-4$ & \\
\hline \multirow{16}{*}{ 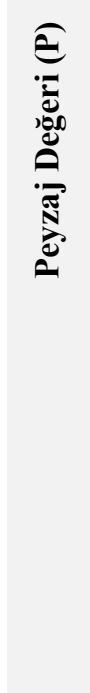 } & & Çalılık, seyrek ağaçlık & $2-3$ & \\
\hline & & Çayırlık & $1-3$ & \\
\hline & Deniz - Göl- Akarsular & Deniz kıyısı & $7-8$ & \\
\hline & & Göl kıyısı & $6-7$ & 8 \\
\hline & & Akarsu kıyısı & $4-5$ & \\
\hline & & Dereler & $1-4$ & \\
\hline & Yüzeysel durum & Düz alan & 5 & \\
\hline & & Hafif dalgalı & 4 & \\
\hline & & Az eğimli, yer yer düzlük & 3 & 5 \\
\hline & & Az engebeli & 2 & \\
\hline & & Orta engebeli & 1 & \\
\hline & Görsel kalite & Panoramik görünümler & $3-4$ & \\
\hline & & Güzel görüş ve Vistalar & $2-3$ & 4 \\
\hline & & Alanın genel görsel estetik değeri & $1-3$ & \\
\hline & Diğer özellikler & $\begin{array}{l}\text { Doğal anıt, çağlayan, mağara, tarihsel ve kültürel değerler, } \\
\text { yaban hayvanları, kuşlar gibi değerleri barındırması }\end{array}$ & $1-6$ & 6 \\
\hline & Toplam puan & & & 35 \\
\hline
\end{tabular}

Formüle göre İklim Değeri: İklim rekreasyon potansiyelini belirlemede en az peyzaj değeri kadar önemlidir. Çünkü iklim koşulları dış mekan kullanım olanağını büyük ölçüde etkiler. Bu nedenle formülde iklim etkisi \% 25 ağırlıkla alınmıştır (Tablo 3).

Formüle göre Ulaşılabilirlik: Rekreasyonel alanlar ancak ulaşılabilir olduklarında kullanılırlar. Bu sebeple kentsel tasarımlar herkes için tasarım olgusu içinde gerçekleştirilmelidir. Her yaştan, cinsiyetten ve engel durumlarına göre kullanıcıların ulaşım kolaylığı sağlanmalıdır. Bu sebeple ulaşılabilirlik öğesi rekreasyon \% 20 bir ağırlıkla formülde değerini almıştır (Tablo 4).

Formüle göre Rekreatif Kolaylık: Rekreatif kolaylık kullanıcıların parkı hangi oranda kullanabileceği durumu ile ilgilidir. Güvenlik, temizlik, otopark gibi etmenler en çok \% 20'lik bir ağırlıkla formülde puanlamada yer almıştır (Tablo 5). 
Tablo 3. İklim Değerini Oluşturan Öğelerin Aldıkları Puanlar (Gülez, 1990: 135)

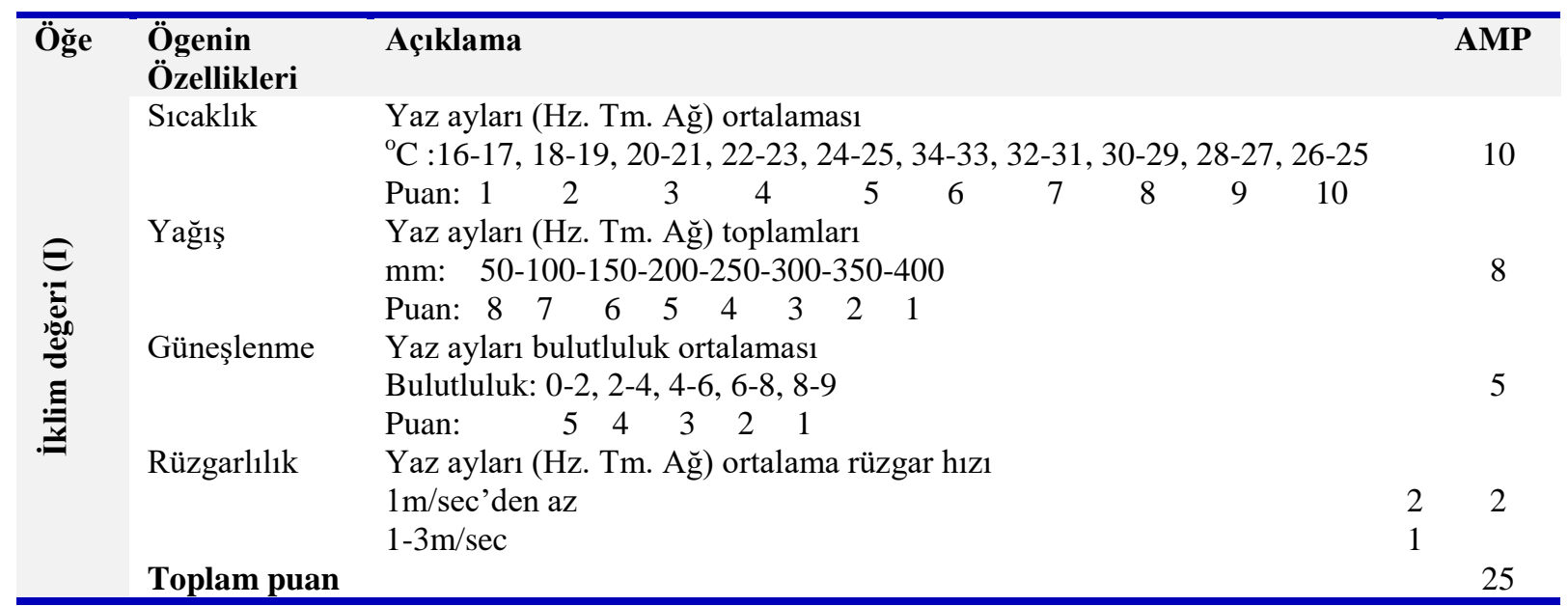

Tablo 4. Ulaşılabilirlik Değerini oluşturan öğelerin aldıkları puanlar (Gülez, 1990: 135-136)

\begin{tabular}{|c|c|c|c|c|}
\hline \multirow[t]{4}{*}{ Öğe } & $\begin{array}{l}\text { Ögenin Özellikleri } \\
\end{array}$ & $\begin{array}{l}\text { Açıklama } \\
\text { (kdeniz } \text { goe Marmara }\end{array}$ & $3-4$ & Amp \\
\hline & & AKdeniz, Ege, Marmara kiyı band1 & $\begin{array}{r}3-4 \\
23\end{array}$ & \\
\hline & önemi & Karadeniz Kiyı band1 & $2-3$ & 4 \\
\hline & & $\begin{array}{l}\text { Önemli karayolu güzergahları, turizmde öncelikli } \\
\text { yerler }\end{array}$ & $1-3$ & \\
\hline \multirow{11}{*}{ 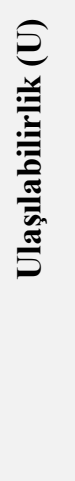 } & Bulunduğu bölgede en az 100.000 & 20km'ye kadar uzaklık & $4-5$ & \\
\hline & nüfuslu kent olmas1 & 50 km'ye kadar uzaklık & $3-4$ & \\
\hline & & 100 km'ye kadar uzaklık & $2-3$ & 5 \\
\hline & & 200 km’ye kadar uzaklık & $1-3$ & \\
\hline & Ulaşım süresi (yakındaki en az & Yürüyerek 1 saate kadar ya da taşıtla $0-1 / 2$ sa & 4 & \\
\hline & 5000 nüfuslu kentten) & Taşitla $1 / 2-1$ saat & 3 & 4 \\
\hline & & Taşıtla 1-2 saat & 2 & \\
\hline & & Taşitla 2-3 saat & 1 & \\
\hline & Ulaşım (taksi ve özel oto dışında) & Yürüyerek gidebilme ya da her an taşıt bulabilme & $3-4$ & \\
\hline & & Belirli saatlerde taşıt bulabilme & $1-3$ & 4 \\
\hline & $\begin{array}{l}\text { Ulaşımda diğer kolaylıklar } \\
\text { Toplam puan }\end{array}$ & Örneğin teleferik olması, denizden ulaşılabilir vb. & $1-3$ & $\begin{array}{c}3 \\
20\end{array}$ \\
\hline
\end{tabular}

Tablo 5. Rekreatif Kolaylıklar Değerini oluşturan öğelerin aldıkları puanlar (Gülez, 1990: 136)

\begin{tabular}{|c|c|c|c|c|}
\hline Öğge & Ögenin Özellikleri & Açıklama & & Amp \\
\hline & Piknik tesisleri & Sabit piknik masa, ocak vb. (niteliklere göre) & $1-4$ & 4 \\
\hline 2 & Su durumu & İçme ve kullanma su durumu & $1-3$ & 4 \\
\hline$\widetilde{\simeq}$ & Geceleme tesisleri & Sabit geceleme tesisleri & 2 & 2 \\
\hline$\cong$ & & Çadırlı geceleme & $1-2$ & 2 \\
\hline $\bar{z}$ & WC'ler & Niteliklerine göre & $1-2$ & 2 \\
\hline$\frac{\pi}{0}$ & Otopark & Niteliklerine göre & $1-2$ & 2 \\
\hline$=$ & Kır gazinosu, satış büfesi & Niteliklerine göre & $1-2$ & 2 \\
\hline 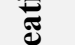 & Bekçi ve görevliler & Sürekli bekçi & 2 & 2 \\
\hline$\underline{\underline{z}}$ & & Hafta sonu bekçi & 1 & 2 \\
\hline & Diğer kolaylıklar & $\begin{array}{l}\text { Plaj, kabin ve duş tesisleri, kiralık sandal olanaklar1, } \\
\text { oyun ve spor alanları, vb. (niteliklerine göre) }\end{array}$ & $1-3$ & 3 \\
\hline & Toplam puan & & & 20 \\
\hline
\end{tabular}


Formüle göre Olumsuz Etkenler: Rekreasyon potansiyelinin belirlenmesinde alanı olumsuz yönde etkileyen etmenler belirlenmeli ve bu etmenler eksi değer olarak yer almalıdır. Formüle göre olumsuz etkenler en çok (-10)' a kadar puan alabilecek şekilde değer almış ve toplamdan olumsuz etkenler çıkartılmıştır (Tablo 6).

Tablo 6. Olumsuz Etkenler Kolaylıklar Değerini Oluşturan Öğelerin Aldıkları Puanlar (Gülez, 1990: 136)

\begin{tabular}{|c|c|c|c|c|}
\hline \multirow{8}{*}{ 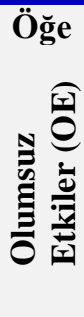 } & Ögenin Özellikleri & \multicolumn{2}{|l|}{ Açıklama } & AMP \\
\hline & Hava kirliliği & Kirlilik derecesine göre & $-1-(-3)$ & -3 \\
\hline & Güvenceli olmaması & Güvence durumuna göre & $-1(-2)$ & -2 \\
\hline & Su kirliliği & Deniz, göl veya akarsular için & -1 & -1 \\
\hline & Bakımsızlık & Alanda yeterli bakımın yapılmaması & -1 & -1 \\
\hline & Gürültü & Trafik, kalabalık, vb. gürültüler & -1 & -1 \\
\hline & Diğer olumsuz etkiler & Taş, çakıl ocakları, inşaat ve fabrika kalıntıları & $-1(-2)$ & -1 \\
\hline & Toplam puan & & & -10 \\
\hline
\end{tabular}

Bahsedilen yöntemin uygulanması sonucunda elde edilen bulgular aldıkları puanlara göre Tablo 7'deki gibi çok düşük, düşük, orta, yüksek ve çok yüksek şeklinde sınıflandırılmıştır.

Tablo 7. Rekreasyon Potansiyeli \% Değerlendirmesi(Gülez, 1990: 139)

\begin{tabular}{ll}
\hline Rekreayonel Potansiyel Değer & Aldığı Puan \\
Rekreasyon potansiyeli çok düşük & $<\% 30$ \\
Rekreasyon potansiyeli düşük & $\% 30-45$ \\
Rekreasyon potansiyeli orta & $\% 45-60$ \\
Rekreasyon potansiyeli yüksek & $\% 61-75$ \\
Rekreasyon potansiyeli çok yüksek & $>\% 75$ \\
\hline
\end{tabular}

\section{Bulgular ve Tartışma}

Çalışma kapsamında 100. Yıl Parkı’nın rekreasyonel potansiyeli Gülez (1990) tarafından geliştirilen yöntemin gerektirdiği tüm kriterler değerlendirilmiş ve hesaplamalar yapılmıştır. Hesaplamalar uzman 11 peyzaj mimarı görüşü alınarak belirlenmiştir. Uzman görüşleri 100. Yıl parkını kullanan ve alanı çok kez ziyaret etmiş kişilerden oluşturulmuştur. Bu değerlendirmelerin sonuçları aşağıdaki gibidir;

Peyzaj değeri; 100.Yıl Parkı yaklaşık 35 ha büyüklügünndedir. Çalışma alanının bitki örtüsü zengin ve ağaç, ağaççık ve çalı formunda doğal birçok bitki türü bulunmakta olması sebebiyle 8 puan olarak hesaplanmıştır. Tarakçı Eren ve Var (2016) çalışmalarında 2016 yılında 100. Yıl parkının tür sayısının 62, bunların 18'inin doğal, 44'ünün egzotik olduğunu ve tür sayısının diğer kent içi parklarına oranla daha fazla olduğu belirtmişlerdir. Çalışmalarında Türk-Japon EYOF Hatıra Parkı'nın da dâhil olduğu alandaki bitki türü bakımından zengin olduğu belirtilmiştir. Bu kapsamda çalışma alanı da EYOF Hatıra Parkı'nı içerdiğinden bitki çeşitliliği bakımından peyzaj değeri yüksek çıkmıştır. Aslında bu alanın bir kısmı önceden çöplük alanı olarak at1l bulunmaktayd.

Park deniz kıyısında ve denize yürüyüş mesafesinde ulaşılabilirliği sebebiyle 8 puan olarak değerlendirilmiştir. Arazi yapısı sebebiyle yer yer düzlük alan olarak nitelendirilebilmektedir. Ancak sahil yoluna sinır olduğu yerlerde alana dolgu toprak taşınarak küçük tepecikler araziyi eğimli yapmıştır. Bu nedenle yüzeysel durumu az meyilli yer yer düz olarak değerlendirilerek 3 puan verilmiştir. Yeşil ve Hacıoğlu'nun (2018) yapmış olduğu çalışmasında görsel kalite park içerisindeki göl ve bitki örtüsü zenginliği olması sebebiyle vista noktaları kabul etmiş ve bu kapsamda görsel kaliteyi 3 puan olarak değerlendirmişlerdir. Benzer şekilde çalışma alanı olarak seçilen parkın deniz ve tabiat manzarası olması sebebiyle 3 puan olarak hesaplanmıştır. Alanın diğer özelliklerine bakıldığında doğal anıt, çağlayan, mağara gibi değerleri bulunmamakta ancak, tarihsel ve kültürel değerler bakımından çeşmeler ve doğal bitki örtüsünü barındırması, kuşların uğrak yeri olması sebebiyle 3 puan olarak değerlendirilmiştir. Genel olarak peyzaj değeri 28 olarak hesaplanmıştır.

İklim değeri; Trabzon ili iki farklı iklim tipine sahip olarak hem deniz hem de dağ esintisine sahip iklim tipi görülmektedir. Kıyı kısmında ılık ve yağışlı bir iklim tipi yaygınken, iç kesimlerde karasal iklim özelliği hâkimdir (Erinç, 1996: 100-150). İklim değeri hesaplanırken alanın en yoğun olarak kullanılan Haziran, Temmuz ve Ağustos ayları değerlendirilmiştir. Buna göre 2000-2018 yılları arası sıcaklık değeri Haziran (20.2), Temmuz (23.1) ve Ağustos (23.2) ayları değerlendirmeye alınarak ortalama sıcaklık $22.1^{0} \mathrm{C}$ olarak 
belirlenmiştir. Bölgenin sıcaklık değeri puanı 4 puan olarak hesaplanmıştır. İklim değerlerinden yağışın rekreatif etkinlikleri olumsuz yönde etkilediğinden ters yönde bir hesaplama yapılmıştır. Trabzon ilinin 20002018 yılları arası yağış miktarı incelendiğinde Haziran ayı 29,8 mm, Temmuz ayı 35,6 mm ve Ağustos ayı 41,9 mm'dir. İlin toplam yağış miktarı ise 106,6 mm olması sebebi ile bölgenin yağış değeri puanı 7 olarak belirlenmiştir. Alanın bulutluluk ortalaması 5,4 gün olası sebebiyle 3 puan, rüzgar hızının 2,7mlsn olduğundan 1 puan olarak belirlenmiştir. İklim değeri belirlenen kriterlerin hesaplanması sonucunda 15 puan olarak belirlenmiştir.

Ulaşılabilirlik; Gülez (1990) yöntemine göre alanın bulunduğu bölgenin turistik önemi Karadeniz kıyı bandında olması sebebiyle 3 puan olarak değerlendirilmiştir. Alanın bulunduğu bölgede en az 100.000 nüfuslu kent olması, kente yaklaşık uzaklığının $7 \mathrm{~km}$ uzaklıkta olması sebebiyle 5 puan almıştır. Alana yürüyerek 1 saate kadar ya da taşıtla 0-1/2 saat mesafede uzakta olduğundan 4 puan, yürüyerek gidebilme ya da her an taşıt bulabilme kriterini sağladığından 3 puan almıştır. Alana özel araç, dolmuş ve otobüs dışında başka bir ulaşım aracı bulunmamaktadır. Ulaşılabilirlik değeri toplamda 15 puanı almıştır.

Rekreatif kolaylıklar; Değerlendirmeler sonucunda park alanı içerisinde sabit piknik masası ve oturma alanlarına ait donatılar bulunduğundan 4 puan, alanda tesis ve satış birimlerinin bulunmaması ve içme suyu sadece çeşmelerden temin edilebilmekte olması sebebiyle 2 puan almıştır. Park alanında geceleme tesisleri bulunamamakta ve niteliklerine göre WC alanı 1 puan, sürekli ve hafta sonu bekçisi de bulunmamaktadır. Park alanının kendine ait bir otoparkı olmamasına karşın yakınındaki AVM ve diğer Türk-Japon EYOF Hatıra Parkı'nın otoparkı rahatlıkla kullanılıyor. Bu nedenle rekreatif kolaylıklar kriteri 8 puan olarak hesaplanmıştır.

Olumsuz etmenler; Olumsuz etmenler park alanının rekreatif faaliyetlerini de olumsuz etkileyen unsurlar. Park bu niteliklerde değerlendirildiğinde 3 tarafından sahil yolu geçmesi nedeniyle hava kirliliğinin az da olsa etkisi altında kalmaktadır. Bu nedenle hava kirliliği -1 olarak değerlendirilmiştir. Park belirli sınırlarda olmayıp özellikle çocuklar için güvenlik sorunu yaratabilmektedir. Güvenlik kriteri bu nedenle -2 değer almıştır. Parka sınır olan deniz kirliliği bulunmamakta, alanda yeterli bakım yapılmamakta -1, trafik sebebiyle gürültülü olması sebebiyle -1 değerlerini almıştır. Formüle göre olumsuz etkiler -5 olarak hesaplanmıştır.

Trabzon 100. Yıl Parkı mevcut hali ile Peyzaj değeri 27, iklim değeri, 15, ulaşım 15, rekreatif kolaylıklar 8 ve olumsuz etkenler -5 olarak hesaplanmıştır (Tablo 8). Gülez (1990) yöntemine göre bu değerlerin toplamı ile elde edilen Rekreasyon Değeri ise \%61 olarak hesaplanmıştır. Sonuç olarak rekreasyon potansiyel değeri \%61 75 arasında hesaplanarak yüksek Alan rekreatif açıdan oldukça potansiyeli yüksek olmasına karşın alanın olumsuz etkilerinin bulunması sebebiyle potansiyeli düşmüştür. Parkın çevresindeki sahil yolunun gürültü ve hava kirliliğine sebep olması, gece kullanımının güvenlik sorunu gibi etmenler özellikle olumsuz kriter olarak değerlendirilmiştir. Sandal ve Karademir (2013) benzer şekilde güvenliğin rekreatif etkinlikler için kullanım şekli ve sıklığını olumsuz etkilediğini belirtmiştir.

Tablo 8. 100. Y1l Parkı'nın rekreasyon potansiyeli

\begin{tabular}{lcc}
\hline Formüldeki öğeler & Alabileceği maksimum puan & Parkın aldı̆̆ı toplam puan \\
Peyzaj değeri & 35 & 28 \\
İklim değeri & 25 & 15 \\
Ulaşılabilirlik & 20 & 15 \\
Rekreatif kolaylık & 20 & 8 \\
Olumsuz etmenler & 0 & -5 \\
Rekreasyon potansiyeli & 100 & 61 \\
\hline
\end{tabular}

\section{Sonuç ve Öneriler}

Rekreasyon, insanların yaşam kalitelerini arttırmada en etkin kavramdır. Çünkü insanlar fiziksel ve ruhsal gereksinimlerini karşılama çabasında olmakta ve boş zamanlarını değerlendirmek için rekreasyonel alanlara yönelmektedirler. İnsanlar dilediği etkinliği, dilediği vakitte ve dilediği biçimde yapabilmelidir. Rekreasyonel etkinlikler yapıldığı mekânlar her türden kullanıcıya hizmet verebilecek nitelikleri taşımalıdır. Bu nedenle kentsel ve kırsal açık alanlarda kullanıcılar için tasarlanan rekreatif etkinlikler ve onları gerçekleştirmek için mekânlar belirli bir planlama ve yönetim dâhilinde olmalıdır. 
Trabzon kenti açık yeşil alanları ve bitki örtüsü ile oldukça zengin bir bölgede yer almaktadır. Kentin sahil alanı olması ve sahil kullanımlarının özellikle son yıllarda artması kentin rekreatif potansiyelinin de artmasına sebep olmuştur. Özellikle kent halkı ilkbahar ve yaz aylarında rekreatif olanaklarına imkân veren mekânlara ihtiyaç duymaktadır. Bu anlamada çalışma alanı olarak seçilen 100. Yıl Parkı kent merkezine yakın ve rekreasyonel anlamda yoğun kullanılan bir alandır. Türk-Japon EYOF Hatıra’nın da çalışma dâhil edilmesi ile bitki tür çeşitliliği bakımından oldukça artmış ve alana değere katmıştır. Çalışma sonucunda yapılan hesaplamalarla parkın rekreasyon potansiyelinin yüksek olduğu belirlenmiştir. Çalışma alanının yeterli büyüklükte olması ve yeşil alanlarının oranının uygun olması, bitki örtüsünün flora ve fauna açısından zengin oluşu, denize kıyısının bulunması, güzel görünüş ve Vista noktalarına sahip olması sebebiyle peyzaj değeri oldukça yüksek olarak belirlenmiştir. Bu anlamda geliştirilen öneriler;

- Çalışmadan elde edilen sonuçlara göre rekreatif etkinliklere engel olabilecek olumsuz etkilerden çevre yolunun geçmesi sonucu hava ve gürültü kirliliğin olduğu saptanmıştır.

- Uzman görüşleri doğrultusunda mevcut tesislerin yetersizliği, alanın bakımsızlığı, çocuk oyun alanlarının yetersizliği ve talebe yönelik kapasiteyi karşılayamaması yeni düzenlemelerin getirilmesini gerektirmektedir.

- Trabzon kent halkının arz-talep doğrultusunda kentlinin rekreasyonel eğilimlerine göre yeni önlemler alınarak düzenlemelerin yapılması gereklidir.

- Rekreatif etkinliklerin geliştirilmesi, özel günlerde şenlikler ve festivaller düzenlenerek rekreasyon alanlarının potansiyelinin artması sağlanabilir.

- Güvenlik sorununu ortadan kaldırmak amacıyla gece aydınlatması sağlanmalıdır.

\section{Kaynaklar}

1. Axelsen M (2009). The power of leisure: I was an anoexic; I'm now a healthy triathlet. Lesiure Sciences. $31,330-346$.

2. Baud-Bovy M, Lawson F (1998). Tourism and recreation handbook of planning and design. Oxford Architectural press, ss. 287.

3. Boman M, Fredman P. Lundmark L, Ericsson G (2013). Outdoor recreation - A necessity or a luxury? Estimation of engel curves for Sweden. Journal Of Outdoor Recreation And Tourism. 3 (4): 49-56

4. Campbell F L (1970). Participant observation in outdoor recreation. Journal of Leisure Research, 2(4): 226-236

5. Çakır G, Çakır A (2012). İğneada Longoz Ormanları Ve Çevresinin Rekreasyonel Faaliyetler Açısından Değerlendirilmesi. KSÜ Doğa Bil. Der, Özel Sayı, 281-286

6. Çalık F, Başer A, Ekinci N M, Kara T (2013). Tabiat parklarının sportif rekreasyon potansiyeli modellemesi (Ballıkayalar Tabiat Parkı örneği). Spor Yönetimi ve Bilgi Teknolojileri Dergisi, 8 (2): 35 51

7. Demirel Ö (1999). A Research on Evaluating For Recreation and Tourism Potential of Natural Resource Values at Çoruh Watershed Area (Yusufeli Region). Turkish Journal of Agriculture and Forestry, 23(EK5): 1103-1112

8. Düzenli T (2018). Çevreyle Bütünleşen- Sürdürülebilir "Cittaslow” Hareketi: Gerze Örneği. Social, Mentality and Researcher Thinkers Journal, 4(11): 307-314

9. Erinç S (1996). Klimatoloji ve Metotları. Alfa Basım Yayım Dağıtım, İstanbul, 538s.

10. Gülez S, Demirel Ö (2004). An evaluation method for the determination of forest recreation potential: a case study. Countryside Recreation, 12 (3): 26-34

11. Gülez S (1983). Kıyısal Alanların Rekreasyonel ve Turistik Yönden Planlamasında Yeni Bir Yaklaşım. Dünya Şehircilik Günü Kıyılar Kollokyumu. Trabzon 
12. Gülez S (1990). Ormaniçi Rekreasyon Potansiyelinin Saptanması İçin Geliştirilen Bir Değerlendirme Yöntemi. İstanbul Üniversitesi Orman Fakültesi Dergisi, 40(2): 133-147

13. Jim C (1989). Visitor Management in Recreation Areas. Environmental Conservation, 16(1): 19-32

14. Karaküçük S (2014). Rekreasyon: boş zamanları değerlendirme. Ss. 355.

15. Karahan F, Orhan T (2009). Çoruh Havzası Uzundere Vadisi'nin Kırsal Rekreasyon Planlaması Yönünden Suya Dayalı Olanakları. Kırsal Çevre Yıllığı 2009, Kırsal Çevre ve Ormancılık Sorunları Araştırma Derneği, s: 55-82, Ankara

16. Kır İ (2007). Yükseköğretim Gençliğinin Boş Zaman Etkinlikleri-KSÜ Örneği, Firat Üniversitesi Sosyal Bilimler Dergisi, 17(2): 307-328

17. Kurar İ, Baltacı F (2014). Halkın boş zaman değerlendirme alışkanlıkları: Alanya Örneği. International Journal of Science Culture and Sport, 2(Special Issue 2), 39-52

18. Öztürk S (2005). Kastamonu-Bartın Küre Dağları Milli Parkının Rekreasyonel Kaynak Değerlerinin İrdelenmesi, Süleyman Demirel Üniversitesi Orman. Fakültesi Dergisi. A(2): 138-148.

19. Pehlivanoğlu M T (1987). Belgrad ormanının rekreasyon potansiyeli ve planlama planlamasının önemi. Peyzaj mimarlı̆̆ dergisi, (3): 45-49

20. Sağcan M (1986). Rekreasyon ve turizm. 380s, Ankara

21. Sandal Ek, Karademir N (2013). Kahramanmaraş İlindeki Günübirlik Rekreasyon Alanlarının Potansiyelinin Belirlenmesi ve Kullanımı İle İlgili Sorunlar. Türk Coğrafya Dergisi, 60: 25-36.

22. Schiller G (2001). Biometeorology and recreation in east mediterranean forest. Landscape and Urban Planning, 57: 1-12

23. Surat H (2017). Gülez Yöntemine Göre Deriner Baraj Gölü ve Yakın Çevresi Rekreasyonel Potansiyelinin Değerlendirilmesi ve Alan Kullanım Önerilerinin Geliştirilmesi. KSÜ Doğa Bilimleri Dergisi, 20(3): 247-257

24. Şimşek D S, Korkut A B (2009). Kıyı Şeridi Rekreasyon Potansiyelinin Belirlenmesinde Bir Yöntem: Tekirdağ Merkez İlçe Örneği. Tekirdağ Ziraat Fakültesi Dergisi. 6(6): 316-327

25. Tarakçı Eren E, Var M (2016). Kent Parklarında Bitkilendirme Tasarımında Kullanılan Bitkiler: Trabzon Örneği. Artvin Orman Fakültesi Dergisi, 17(2): 200-213

26. Türkmen M, Kul M, Genç E, Sarıkabak M (2013). Konaklama İşletmesi Yöneticilerinin Rekreasyon Alg1 Ve Tutumlarının Değerlendirilmesi: Batı Karadeniz Bölgesi Örneği, Turkish Studies - International Periodical For The Languages, Literature and History of Turkish or Turkic Volume 8/8: 2139-2152

27. Tütüncü, Ö., Aydın, İ., Küçükusta, D., Avcı, N., Taş, İ (2011). Üniversite öğrencilerinin rekreasyon faaliyetlerine katılımını etkileyen unsurların analizi. Spor Bilimleri Dergisi, 22(2), 69-83.

28. Yeşil M, Beyli K N (2018). Ordu-Boztepe's Tourism and Recreation Potential with Boztepe's Contribution on the City Image. Turkish Journal of Agriculture-Food Science and Technology, 6(3), 291298

29. Yeşil P, Hacıoğlu V (2018). Limni Gölü Tabiat Parkı Peyzaj Değerlerinin Rekreasyonel Açıdan Değerlendirilmesi. Turkish Journal of Agriculture: Food Science and Technology, 6(6), 680-688

30. Yılmaz O, Kurum E, Akpınar N (1996). Ankara metropolitan kent halkının rekrasyonel eğilimleri ve kent yakın çevresi açık-yeşil alanları ile ilişkileri. Çevre planlama ve tasarımına bütüncül yaklaşım sempozyum kitab1,248-2 